\title{
0150 RESULTS OF THE PRE, POST AND MIDYEAR TESTS OF THE WALK THIS WAY SAFE KIDS PHILIPPINES
}

A C Rolloque*, R Consunji, M Alcantara, M T A Perez, J Rolloque Correspondence: Safe Kids Worldwide Philippines, 3F Cargohaus Bldg. Brgy. Vitales NAIA Complex, Paranaque City, 1700, Philippines

10.1136/ip.2010.029215.150

Objectives To know the level of knowledge of the students who received road safety education after 3 months in the urban city of the Philippines.

Methods Safe Kids Philippines used the standard pre- and post-test tools to students of public elementary schools. The volunteers went to schools and administered the pretests to students before giving them a lesson regarding road safety which lasted for $45 \mathrm{~min}$ to $1 \mathrm{~h}$, after these children administered the post-tests to examine if there is an increase on the knowledge of road safety. These data were tabulated. After 3 months the volunteers went back to these students without giving any classroom teachings or review on road safety education but just administer the midyear post-tests to know if the knowledge were retained.

Results Based on the data gathered by Safe Kids Philippines it came out that children who attended the classroom teachings on road safety got a higher score in the post-tests after the classroom teachings comparing to their scores on the pretests. There was an increase of knowledge to $25-36 \%$ per question that were given to them. After 3 months, they administered the midyear post-tests, some of the students scores are still increasing but in a very low percentage of $1-10 \%$ increase of knowledge and some even decrease the level of knowledge.

Conclusions It can be concluded that although there is an increase on the knowledge of road safety of the students after the administration of pre-, post- and midyear post-tests there is a need to reinforce the education to these children if we really want these children be safer on road injuries. 